\title{
THE DESCRIPTIVE AND NORMATIVE VERSIONS OF SCIENTIFIC REALISM AND PESSIMISM ${ }^{1}$
}

SEUNGBAE PARK, Ulsan National Institute of Science and Technology, Ulsan, Republic of Korea PARK, S.: The Descriptive and Normative Versions of Scientific Realism and Pessimism

FILOZOFIA, 74, 2019, No 4, pp. $278-290$

Descriptive realism holds that $\mathrm{T}$ is true, while normative realism holds that $\mathrm{T}$ is warranted. Descriptive pessimism holds that $\mathrm{T}$ is false, while normative pessimism holds that $\mathrm{T}$ is unwarranted. We should distinguish between descriptive and normative realism because some arguments against scientific realism require that scientific realism be interpreted as descriptive realism, and because scientific realists can retreat from descriptive to normative realism when descriptive realism is under attack. We should also distinguish between descriptive and normative pessimism because some arguments against scientific pessimism require that it be interpreted as descriptive pessimism, and because scientific pessimists can retreat from descriptive to normative pessimism when descriptive pessimism is under attack.

Keywords: No-Miracles argument - Pessimistic induction - Scientific realism Scientific pessimism

\section{Introduction}

Scientific realism and pessimism are opposing views about $\mathrm{T}$, one of our best current theories. The literature presents descriptive and normative versions of scientific realism, which I call descriptive realism and normative realism, respectively. Descriptive realism holds that $\mathrm{T}$ is true, ${ }^{2}$ while normative realism holds that $\mathrm{T}$ is warranted. There are also descriptive and normative versions of scientific pessimism, which I call descriptive pessimism and normative pessimism, respectively. Descriptive pessimism holds that $\mathrm{T}$ is false, while normative pessimism holds that $\mathrm{T}$ is unwarranted. It is vitally important to distinguish between descriptive and normative realism, and between descriptive and normative pessimism.

\footnotetext{
${ }^{1}$ I thank Mr. Jihee Han at UNIST and anonymous referees of this journal for useful comments. This work was supported by the Ministry of Education of the Republic of Korea and the National Research Foundation of Korea (NRF-2018S1A5A2A01039606).

2 This paper drops 'typically' and 'approximately' for the sake of brevity.
} 
I use the terms 'descriptive pessimism' and 'normative pessimism' instead of the terms 'descriptive antirealism' and 'normative antirealism' for the following two reasons. First, descriptive pessimism and normative pessimism originate from the pessimistic induction as will become clear in Section 3. Second, 'antirealism' refers to any position that opposes realism. Thus, 'antirealism' refers not only to the positions that $\mathrm{T}$ is false and unwarranted, but also to the positions that $\mathrm{T}$ is empirically adequate, that it is warranted that $\mathrm{T}$ is empirically adequate, and so forth. So 'antirealism' is a more inclusive term than 'pessimism'.

I undertake the following tasks in this paper. In Section 2, I point out that both descriptive and normative realism can be found in the no-miracles argument (Putnam, 1975). I argue that they have different capacities, that some objections to scientific realism depend upon scientific realism being descriptive realism, and that the downfall of descriptive realism does not necessarily mean the downfall of normative realism. In Section 3, I argue that there are descriptive and normative versions of the pessimistic induction (PI), and hence that there are also descriptive and normative pessimism. I show that descriptive pessimism is more vulnerable to attack from scientific realists than normative pessimism is. I argue that the consideration of the PI can lead to the distinction between descriptive and normative realism, and between descriptive and normative empiricism. In Section 4, I explicate how Bas van Fraassen's (1980) definitions of scientific realism and constructive empiricism relate to the aforementioned four positions.

Anjan Chakravartty (2017) and Darrell Rowbottom (2017) present comprehensive overviews of dialectical terrains concerning scientific realism. Such papers are useful to both new participants and veterans in the scientific realism debate. This paper, however, arises from the observation that these two survey articles do not distinguish between descriptive and normative realism, nor between descriptive and normative pessimism. The literature has neglected these distinctions, despite the fact that the scientific realism debate has been vigorous and voluminous for the past several decades.

\section{The No-Miracles Argument}

The no-miracles argument (NMA) is the most famous consideration for scientific realism (Sankey 2017, 201). This section aims to show that both descriptive and normative realism inhere in the NMA, and that some arguments regarding scientific realism only make sense under the interpretation that it is descriptive realism, and not under the interpretation that it is normative realism.

There are successful theories in science, such as general relativity, evolutionary theory, and special relativity. Why are they successful? An answer can be found in Hilary Putnam's NMA: 
The positive argument for realism is that it is the only philosophy that doesn't make the success of science a miracle. That terms in mature scientific theories typically refer (this formulation is due to Richard Boyd), that the theories accepted in a mature science are typically approximately true, that the same term can refer to the same thing even when it occurs in different theories - these statements are viewed by the scientific realist not as necessary truths but as part of the only scientific explanation of the success of science, and hence as part of any adequate scientific description of science and its relations to its objects (Putnam 1975, 73).

Descriptive realism is explicit in the last sentence of this passage. According to Putnam, scientific realism describes science. What about normative realism? It is implicit in the first sentence of the passage above. Putnam's assertion that the successful performance of theories would be a miracle, if they were false, implies that it is unreasonable to believe that they are false, and that their successful performance would not be a miracle, if they were true, implies that it is reasonable to believe that they are true. To say that it is reasonable to believe that they are true is to be committed to normative realism. In sum, both descriptive realism and normative realism can be found in the NMA.

How do descriptive and normative realism differ? A fundamental difference is that descriptive realism is capable of being true or false, whereas normative realism is not. Descriptive realism would be true if $\mathrm{T}$ is as descriptive realism holds it to be, i.e., if $\mathrm{T}$ is true, and false if $\mathrm{T}$ is not as descriptive realism holds it to be, i.e., if $\mathrm{T}$ is false. $\mathrm{T}$ is directly rendered true or false by the world. Consequently, descriptive realism is indirectly rendered true or false by the world. By contrast, normative realism, because it is a normative thesis, is not capable of being true or false. Even if T happens to be true, it is an open question whether it is warranted or not, as will become clear in the next section.

A derivative difference between descriptive and normative realism is that the former can explain the success of $\mathrm{T}$, but the latter cannot. It makes sense to say, for example, that the meta-hypothesis that $\mathrm{T}$ is true explains why $\mathrm{T}$ makes true predictions, i.e., it makes sense to say that $\mathrm{T}$ makes true prediction because it is true. By contrast, it is conceptually problematic to say that the meta-hypothesis that $\mathrm{T}$ is warranted explains why it makes true predictions, i.e., it is conceptually problematic to say that $\mathrm{T}$ makes true predictions because it is warranted. We should rather say that $\mathrm{T}$ is warranted, if at all, because it makes true predictions. Since descriptive realism and normative realism have different capacities, we should distinguish between them.

The importance of distinguishing between descriptive and normative realism looms once we consider three famous objections to the NMA. The first famous 
objection is that the NMA begs the question against the critics of abduction. The critics disbelieve that abduction is a reliable rule of inference. The NMA, however, relies on abduction, so it would not convince them. For this reason, Larry Laudan and Arthur Fine characterize the NMA, respectively, as "a monumental case of begging the question" (Laudan 1981, 45) and as "a paradigm case of ging the question" (Fine 1991, 82).

These two philosophers start with the assumption that scientific realism is descriptive realism, which explains the success of $\mathrm{T}$, and then contend that descriptive realism rests upon a circular argument. To say that descriptive realism is unwarranted means that $\mathrm{T}$ is unwarranted, which is exactly what normative pessimism affirms. Thus, Laudan and Fine set out to criticize descriptive realism and end up accepting normative pessimism.

The second famous objection is that the NMA is undermined by alternative accounts of the success of T. ${ }^{3}$ Critics of the NMA might propose, for example, that the empirical adequacy of $\mathrm{T}$ accounts for its success (Ladyman 1999, 186), or that the behavior of observables accounts for the success of T (Mizrahi 2012, 137; Lyons 2018, 147). These alternative explanations do not appeal to a miracle to explain the success of T. Thus, their existence undermines Putnam's contention that scientific realism "is the only philosophy that doesn't make the success of science a miracle" (Putnam 1975, 73).

The critics of the NMA start with the assumption that scientific realism is descriptive realism, which explains the success of $\mathrm{T}$, and then claim that descriptive realism is unwarranted due to the existence of the alternative hypotheses that do not appeal to the truth of $\mathrm{T}$. To say that descriptive realism is unwarranted is to say that $\mathrm{T}$ is unwarranted, which is exactly what normative pessimism affirms. Thus, they set out to criticize descriptive realism and end up accepting normative pessimism.

The third famous objection is that historical counterexamples undercut scientific realism (Laudan 1981, 47 - 48). The idea is that some false theories were successful, and these all run counter to the thesis that every successful theory is true. Lyons formulates this objection as follows:

1. If (a) that realist meta-hypothesis were true, then (b) we would have no successful theories that cannot be approximately true. (If we did, each would be a "miracle," which no one of us accepts.)

2. However, (no-b) we do have successful theories that cannot be approximately true: the list (of "miracles").

3. Therefore, (no-a) the realist meta-hypothesis is false. (And the no-miracles argument put forward to justify that meta-hypothesis is unacceptable.) (Lyons 2016, 566)

\footnotetext{
${ }^{3}$ See Park (2014) for a critical discussion of nine antirealist accounts.
} 
This argument is a modus tollens. It has the same form as the following argument: If all apples were red, there would be no white apples, but there are some white apples; thus, it is false that all apples are red. In other words, white apples exist, and they are all counterexamples to the general statement that all apples are red. It follows that we should be agnostic about whether the next apples will be red. Laudan and Lyons's argument is similarly intended to establish that we should be agnostic that current theories are true. Their argument is not intended to establish that current theories are false. For this reason, Park (2019a; Section 4.3) calls it the agnostic deduction.

As far as I can tell, Laudan and Lyons start with the assumption that scientific realism is descriptive realism, and then contend that the historical counterexamples show that descriptive realism is false, i.e., that it is false that every successful theory is true. Thus, current theories might be true or might be false, and we do not know whether they are true or false, which means that they are unwarranted, and that is exactly what normative pessimism affirms. Therefore, we can say that Laudan and Lyons set out to criticize descriptive realism and end up accepting normative pessimism.

Let me now turn to writers who take scientific realism to be normative realism. Timothy Lyons defines scientific realism as the view that "we can justifiably believe the hypothesis that successful theories are approximately true" (Lyons 2005, 171). Lyons $(2016,564 ; 2017,1 ; 2018,148)$ gives similar formulations of scientific realism. K. Brad Wray interprets Philip Kitcher's (2001) scientific realism as claiming that "there is a strong connection between success and truth that warrants our believing that our successful theories are true" (Wray 2013, 1722). Thomas Nickles embraces non-realism, according to which we do not "have sufficient evidence and argument to conclude with confidence that even our most mature theories are true, or very nearly, that at best minor tweaking will be necessary" $(2017,151)$. Thus, Nickles would define scientific realism as the thesis that we have enough evidence to conclude so. These three philosophers' formulations of scientific realism all come down to the suggestion that $\mathrm{T}$ is warranted, which is exactly what normative realism asserts. Thus, they would define scientific pessimism as the view that $T$ is unwarranted, which is exactly what normative pessimism asserts.

In line with Lyons, Wray, and Nickles are other philosophers, such as David Papineau (1996), Alan Musgrave (2017, 2018), and van Fraassen (2017). Papineau takes constructive empiricism to be the thesis that "we ought never to believe in the truth of any theory which goes beyond the observable phenomena" $(1996,8)$. Given that Papineau takes constructive empiricism to be a normative thesis, he would also take scientific realism to be the corresponding normative thesis that the belief of $\mathrm{T}$ is 
reasonable. According to Musgrave, scientific realism asserts that "it is reasonable to believe that $\mathrm{H}$ is true" (Musgrave 2017, 80). Van Fraassen replies that "such a belief is reasonable enough, but supererogatory" $(2017,102)$. Note that both Musgrave and van Fraassen contend that the belief of $\mathrm{H}$ is reasonable. In sum, all these three philosophers would take scientific realism to be normative realism.

It is conceptually problematic to suggest that $T$ is successful because the belief of $\mathrm{T}$ is reasonable. As noted above, Lyons, Wray, Nickles, Papineau, Musgrave, and van Fraassen, take scientific realism to be normative realism. As a result, they would not say that scientific realism explains the success of $\mathrm{T}$. If they happen to say so, however, we should interpret them as saying that descriptive realism explains the success of $\mathrm{T}$.

Earlier in this section, I introduced the three famous objections to descriptive realism. Recall that by attacking descriptive realism, the objectors all end up embracing normative pessimism. The demise of descriptive realism, however, does not ne-cessarily lead to normative pessimism, given that there are alternative positions, viz., normative realism and descriptive pessimism. An interesting question is whether the three objections count as convincing reasons for rejecting normative realism. Should we reject normative realism because the no-miracles argument is circular, because there are alternative accounts of the success of $\mathrm{T}$, or because some successful theories were false in the history of science? This question can trigger interesting debates between normative realists and their opponents. Unfortunately, it would take us too far afield to stake out a position in this intriguing territory.

This paper only offers an outline of how debates between normative realists and their opponents could unfold. Regarding the problem of circularity, normative realists could reply that new positive arguments for descriptive realism are introduced into the literature (Park 2018a, Section 3; 2018b, 57; 2018c, Section 3; 2019b, Section 3; 2019c, Section 4, 2019d, Section 4).

Such new arguments might amount to a defense of normative realism. Regarding the alternative accounts, normative realists could object that the alternative accounts are all problematic (Park 2014). Successful refutations of the alternative accounts would make normative realism promising. Regarding the agnostic deduction, they could argue that current theories are far more successful than their predecessors, so the falsity of the predecessors does not have enough power to make current theories unwarranted. All these contentions would be disputed by critics of normative realism. It would require, however, a lengthy digression to sketch the dialectic between them. This paper only needs the thesis that the demise of descriptive realism does not necessarily lead to the demise of normative realism. 


\section{The Pessimistic Induction}

The PI, another important argument in the realism debate, is the main consideration against scientific realism (Sankey 2017, 201). This section aims to show that there are descriptive and normative versions of the PI, which implies that there are descriptive and normative pessimism. We should distinguish between descriptive and normative pessimism because normative pessimism is a safer position than descriptive pessimism.

The descriptive PI holds that just as $\mathrm{T}_{1}$ was false, so $\mathrm{T}_{2}$ is false, where the former is a past theory and the latter is a present theory. This version of the PI can be inferred from Putnam's formulation of the PI that "Just as no term used in the science of more than fifty (or whatever) years ago referred, so it will turn out that no term used now (except maybe observational terms, if there are such) refers" $(1978,25)$. The descriptive PI can also be inferred from Stathis Psillos's formulation of the PI that "if most past successful scientific theories turned out to be false, then, by induction on scientific theories, one must not just remain agnostic, but rather claim that current successful scientific theories are likely to be false" $(1995,16)$. Keep in mind that the descriptive PI asserts that $\mathrm{T}_{2}$ is false.

In contrast, the normative PI holds that just as $T_{1}$ was unwarranted, so $T_{2}$ is unwarranted. The normative PI is neutral about the truth-value of $T_{2}$. It says that $\mathrm{T}_{2}$ might be true, and that even though $T_{2}$ is true, we cannot justifiably believe that it is true. No one has directly formulated the PI in this manner in the literature. It, however, can be inferred from James Ladyman's formulation that "reflection on the abandonment of theories in the history of science motivates the expectation that our best current scientific theories will themselves be abandoned, and hence that we ought not to assent to them" (Ladyman 2014). To say that we ought not to assent to present theories is to say that $T_{2}$ is unwarranted.

Descriptive and normative pessimism can be found in the descriptive PI and the normative PI, respectively. Descriptive pessimism accords with the conclusion of the descriptive PI, and normative pessimism with that of the normative PI. In addition, descriptive pessimism is the pessimist counterpart of descriptive realism, and normative pessimism that of normative realism.

Both the descriptive PI and the normative PI should be distinguished from the skeptical inference that since $T_{1}$ was false, $T_{2}$ is unwarranted. Recall that the descriptive PI holds that since $T_{1}$ was false, $T_{2}$ is false. The premise and the conclusion are similar to each other in that they make definite claims about $\mathrm{T}_{1}$ and $\mathrm{T}_{2}$, respectively. Recall that the normative PI holds that since $T_{1}$ was unwarranted, $T_{2}$ is unwarranted. The premise and the conclusion are also similar to each other in that they make skeptical claims about $\mathrm{T}_{1}$ and $\mathrm{T}_{2}$, respectively. By contrast, the premise and the conclusion 
of the skeptical inference above dissimilar to each other in that the former makes a definite claim about $T_{1}$, but the conclusion makes a skeptical claim about $T_{2}$.

This skeptical inference exemplifies skepticism about induction (Park 2019a, Section 4.2; forthcoming, Section 3). Humean skeptics reason, for example, that since some apples have fallen down, we do not know whether the next apple will fall down or not. Note that the premise of this skeptical inference makes the definite claim about some apples, but the conclusion makes a skeptical claim about the next apple. Humean skeptics reject, while scientific pessimists accept, the uniformity principle (Hume, 1888/1978, 89) that the future is similar to the past. So if a premise says that $T_{1}$ was false, Humean skeptics infer that $T_{2}$ is false, and if a premise says that $T_{1}$ was unwarranted, they infer that $T_{2}$ is unwarranted.

Now that we are clear about the distinction between a pessimistic inference and a skeptical inference, we are ready to discuss the distinction between descriptive and normative pessimism. Why should we distinguish between descriptive and normative pessimism? Several objections were raised against scientific pessimism in the literature, and they require that scientific pessimism be interpreted as descriptive pessimism. It is worth examining them in detail one by one.

Let me begin with a standard criticism against the descriptive PI. It asserts that $\mathrm{T}_{1}$ explains and predicts more phenomena than $T_{2}$, so it is a fallacious inference that since $T_{1}$ was false, $T_{2}$ is also false (Musgrave 1985, 211; Devitt 2011, 292). Note that this criticism targets descriptive pessimism. In the face of this criticism, scientific pessimists tend to retreat from descriptive to normative pessimism, i.e., they tend to admit that $\mathrm{T}_{2}$ might be true, but maintain that $\mathrm{T}_{2}$ is unwarranted (Park 2019a, Section 4.2). On their account, the fact that $T_{1}$ was false does not make $T_{2}$ likely to be false, but makes $T_{1}$ unwarranted. Their move indicates that descriptive pessimism is more susceptible to attack than normative pessimism.

Another standard realist objection to the descriptive PI asserts that the PI commits the fallacy called the fallacy of biased statistics (Fahrbach 2011; Park 2011; Mizrahi 2013). Pessimists provide a list of past theories to justify the premise of the descriptive PI. The list, however, favors distant past theories, e.g., the miasma theory, while failing to include any recent past theory, e.g., the kinetic theory. Note that this criticism also targets descriptive pessimism. In this face of this objection, scientific pessimists can retreat from descriptive to normative pessimism. Their retreat indicates that normative pessimism is a safer position than descriptive pessimism.

Consider also the following confrontation between descriptive realists and pessimists. Suppose that there are five successive theories of disease, $T_{1}, T_{2}, T_{3}, T_{4}$, and $T_{5} . T_{1}$ and $T_{2}$ have been rejected, and $T_{3}$ is currently accepted. Scientists will need to remove $T_{3}$ and $T_{4}$ before arriving at the true theory, $T_{5}$. They, however, do not know 
that they need to remove more theories before arriving at the true theory. Under such epistemic circumstances, descriptive pessimists would argue that scientists need to remove more theories, including $\mathrm{T}_{3}$, before obtaining the true theory, and hence that $T_{3}$ is false. On their account, the demise of $T_{1}$ and $T_{2}$ does not make it likely that $T_{3}$ is true. Descriptive realists, however, would retort that scientists have already removed enough theories, so $T_{3}$ is true. On their account, the demise of $T_{1}$ and $T_{2}$ makes it likely that $\mathrm{T}_{3}$ is true. Note that the more theories that have been discarded, the better it is for descriptive realism, and the fewer theories that have been discarded, the better it is for descriptive pessimism. We do not know whether the number of discarded theories is large enough to establish descriptive realism, or small enough to establish descriptive pessimism. Thus, we do not know whether the history of science favors descriptive realism or descriptive pessimism (Park 2019a, Section 3.1).

This stalemate between descriptive realists and pessimists might motivate scientific pessimists to retreat from the strong position that $\mathrm{T}_{3}$ is false to the weaker position that $\mathrm{T}_{3}$ is unwarranted. They admit that $\mathrm{T}_{3}$ might be true, but maintain that scientists are in the unfortunate epistemological situation in which they do not know that $T_{3}$ is true. The gloomy history of science constitutes their reason for skepticism about current theories (Park, 2019a: Section 4.2). Note that scientific pessimists are willing to give up descriptive pessimism, but not normative pessimism, which indicates that normative pessimism less vulnerable to attack than descriptive pessimism. Therefore, we should distinguish between them.

The foregoing stalemate between descriptive realists and pessimists might also motivate scientific realists to retreat from the strong position that $T_{3}$ is true to the weaker position that $\mathrm{T}_{3}$ is warranted. They admit that $\mathrm{T}_{3}$ might be false, but maintain that scientists are in the fortunate epistemological situation in which the history of science constitutes the reason for believing that $\mathrm{T}_{3}$ is true (Park 2019a, Section 4.2). The history of science is favorable to scientific realists because the demise of $T_{1}$ and $T_{2}$ makes it likely that $T_{3}$ is true. On their account, scientists have made enough mistakes. Consequently, $T_{3}$ is warranted. Note that scientific realists are willing to give up descriptive realism, but not normative realism, which indicates that it is harder to establish descriptive realism than normative realism. Therefore, we should distinguish between them.

Finally, it is also useful to distinguish between descriptive and normative empiricism. Descriptive empiricism holds that $\mathrm{T}$ is empirically adequate, while normative empiricism holds that we are warranted in believing that $\mathrm{T}$ is empirically adequate. These two positions should be kept distinct, just as descriptive realism and normative realism should be kept distinct. There are some objections to descriptive empiricism. For example, a pessimistic induction asserts that since T's precursor was empirically inadequate, $\mathrm{T}$ is also empirically ina- 
dequate (Park, 2018a: 337). In the face of this objection, empiricists might retreat from descriptive empiricism to normative empiricism. I, however, leave to interested readers the task of fleshing out this line of thinking.

\section{Van Fraassen's Definitions}

How does van Fraassen (1980) define scientific realism and constructive empiricism? How do his definitions of these rivaling positions relate to the definitions of descriptive realism and pessimism, and to the definitions of normative realism and pessimism? ${ }^{4}$

Van Fraassen's (1980) definitions of the two rivaling positions are not about whether $\mathrm{T}$ is true or false, whether $\mathrm{T}$ is warranted or unwarranted, whether $\mathrm{T}$ is empirically adequate or inadequate, or whether it is warranted or unwarranted that $\mathrm{T}$ is empirically adequate. They are rather about what science pursues, and what acceptance of T involves. Specifically, scientific realism holds that science "aims to give us, in its theories, a literally true story of what the world is like; and acceptance of a scientific theory involves the belief that it is true" (van Fraassen 1980, 8). Constructive empiricism holds that science "aims to give us theories which are empirically adequate; and acceptance of a theory involves as belief only that it is empirically adequate" (van Fraassen 1980, 12).

What does it mean to accept a theory? Van Fraassen answers that to accept a theory means to "confront any future phenomena by means of the conceptual resources of this theory" (van Fraassen 1980, 12). Thus, according to scientific realism, scientists believe that $\mathrm{T}$ is true when they use it to investigate the world. According to constructive empiricism, by contrast, scientists believe that $\mathrm{T}$ is empirically adequate when they use it to investigate the world. This difference between the two rivaling positions is not well-appreciated in the literature. The two rivaling positions make different claims about what scientists believe with respect to $T$ when they use it to investigate the world.

What do the advocates of the two rivaling positions debate over? They debate over whether science has the goal to achieve true or empirically adequate theories, and over whether scientists believe that $\mathrm{T}$ is true or empirically adequate. Consequently, we should not expect that they would take positions on the issues of whether $\mathrm{T}$ is true or false, whether it is warranted or unwarranted, whether it is empirically adequate or inadequate, or whether it is warranted or unwarranted that $\mathrm{T}$ is empirically adequate.

Van Fraassen can assert that $\mathrm{T}$ is unwarranted, and that $\mathrm{T}$ is empirically adequate. When he makes such assertions, however, he is not a constructive empiricist. After all, the assertions are not entailed by the view that science "aims to give us

${ }^{4}$ I thank a reviewer of this journal for this question. 
theories which are empirically adequate; and acceptance of a theory involves as belief only that it is empirically adequate" (van Fraassen 1980, 12). It is one thing to say that science seeks empirically adequate theories, and that scientists believe that $\mathrm{T}$ is empirically adequate when they use it to investigate the world. It is quite another to say that $\mathrm{T}$ is unwarranted, and that $\mathrm{T}$ is empirically adequate. An argument is required to make an inference from the former contentions to the latter contentions.

\section{Conclusion}

Rival philosophers construct various arguments against scientific realism and pessimism in the literature. Some objections to scientific realism requires that it be interpreted as descriptive realism. These objections may prod scientific realists to retreat from descriptive to normative realism. Some objections to scientific pessimism also require that it be interpreted as descriptive pessimism. These objections may also prod scientific pessimists to retreat from descriptive to normative pessimism. Therefore, we should distinguish between descriptive and normative realism, and between descriptive and normative pessimism.

Which of the foregoing four views about $\mathrm{T}$ should the participants in the realism debate choose as their framework? The answer depends on what interests them. If they are interested in whether $\mathrm{T}$ is true, they should choose descriptive realism and pessimism as the framework of their debate. If they are interested in whether $\mathrm{T}$ is warranted, they should choose normative realism and pessimism as the framework of their debates. If they are interested in both, they may choose any of the four views.

\section{Bibliography}

DEVITT, M. (2011): “Are Unconceived Alternatives a Problem for Scientific Realism?” Journal for General Philosophy of Science, 42 (2), 285 - 293.

FAHRBACH, L. (2011): "How the Growth of Science Ends Theory Change". Synthese, 180 (2), 139 $-155$.

FINE, A. (1991): "Piecemeal Realism". Philosophical Studies, 61 (1-2), 79 - 96.

HUME, D. (1888/1978): A Treatise of Human Nature. Selby-Bigge, L. A. - Nidditch, P. H. (eds.), Oxford: Oxford Uni-versity Press.

CHAKRAVARTTY, A. (2017): "Scientific Realism". The Stanford Encyclopedia of Philosophy. Zalta, E. N. (ed.). URL $=<$ https://plato.stanford.edu/archives/sum2017/entries/scientific-realism/>.

KITCHER, Ph. (2001): "Real Realism: The Galilean Strategy". Philosophical Review, 110 (2), 151 $-197$.

LADYMAN, J. (1999): Review of Leplin's. A novel defense of scientific realism. British Journal for the Philosophy of Science, 50 (1), $181-188$.

LADYMAN, J. (2014): "Structural Realism". In: The Stanford Encyclopedia of Philosophy. Zalta, E. N. (ed.). URL $=<$ https://plato.stanford.edu/archives/win2016/entries/structural-realism/>. 
LAUDAN, L. (1977): Progress and Its Problems: Towards a Theory of Scientific Growth. California: University of California Press.

LAUDAN, L. (1981). “A Confutation of Convergent Realism”. Philosophy of Science, 48 (1), 19 - 49.

LYONS, T. (2005): “Toward a Purely Axiological Scientific Realism”. Erkenntnis, 63 (2), 167 204.

LYONS, T. (2016): “Scientific Realism”. In: Humphreys, P. (ed.): The Oxford Handbook of Philosophy of Science. New York: Oxford University Press: 564 - 584.

LYONS, T. (2017): "Systematicity Theory Meets Socratic Scientific Realism: The Systematic Quest for Truth". Synthese. https://doi.org/10.1007/s11229-017-1561-2.

LYONS, T. (2018): "Four Challenges to Epistemic Scientific Realism". Spontaneous Generations: A Journal for the History and Philosophy of Science, 9 (1), 146 - 150.

MIZRAHI, M. (2012): "Why the Ultimate Argument for Scientific Realism Ultimately Fails". Studies in History and Philosophy of Science Part A, 43 (1), 132 - 138.

MIZRAHI, M. (2013). “The Pessimistic Induction: A Bad Argument Gone Too Far”. Synthese, 190 (15), $3209-3226$.

MUSGRAVE, A. (1985): “Realism vs. Constructive Empiricism”. In: Churchland, P. M. - Hooker, C. A. (eds.): Images of Science: Essays on Realism and Empiricism. Chicago: The University of Chicago Press.

MUSGRAVE, A. (2017): "Strict Empiricism Versus Explanation in Science". In: Agazzi, E. (ed.): Varieties of Scientific Realism: Objectivity and Truth in Science. Basel: Springer International Publishing, $71-93$.

MUSGRAVE, A. (2018): "Beware of Bad Dog Realist". Spontaneous Generations, 9, 152 - 164.

NICKLES, Th. (2017): "Cognitive Illusions and Nonrealism: Objections and Replies". In: Agazzi, E. (ed.): Varieties of Scientific Realism: Objectivity and Truth in Science. Basel: Springer International Publishing, $95-108$.

PAPINEAU, D. (1996): The Philosophy of Science. Oxford: Oxford University Press.

PARK, S. (2011): "A Confutation of the Pessimistic Induction”. Journal for General Philosophy of Science, 42 (1), $75-84$

PARK, S. (2014): “A Pessimistic Induction against Scientific Antirealism”. Organon F, 21 (1), 3- 21.

PARK, S. (2018a): “The Anti-Induction for Scientific Realism”. Grazer Philosophische Studien, 95 (3), $329-342$.

PARK, S. (2018b): "Justifying the Special Theory of Relativity with Unconceived Methods". Axiomathes, 28 (1), $53-62$.

PARK, S. (2019a): "New Objections to the Problem of Unconceived Alternatives". Filosofia Unisinos, 20 (2), (to be assigned).

PARK, S. (2019b): "Localism vs. Individualism for the Scientific Realism Debate”. Philosophical Papers. https: //doi.org/10.1080/05568641.2018.1500144.

PARK, S. (2019c): “Optimistic Realism over Selectivism”. Kriterion: Journal of Philosophy, 31 (1), $89-106$.

PARK, S. (2019d): "The Coherence of Evolutionary Theory with Its Neighboring Theories". Acta Biotheoretica: Mathematical and Philosophical Foundations of Biological and Biomedical Science. DOI: 10.1007/s10441 -019-09341-3.

PARK, S. (forthcoming): "Scientific Realism and the Future Development of Science". Diametros (to be assigned).

PSILLOS, S. (1995): “Is Structural Realism the Best of Both Worlds?” Dialectica, 49 (1), 15 - 46. 
PUTNAM, H. (1975): Mathematics, Matter and Method: Philosophical Papers Volume I. Cambridge: Cambridge University Press.

PUTNAM, H. (1978): Meaning and the Moral Sciences. London: Routledge \& K. Paul.

ROWBOTTOM, D. (2017): "Scientific Realism: What It Is, the Contemporary Debate, and New Directions". Synthese. https://doi.org/10.1007/s11229-017-1484-y.

SANKEY, H. (2017): "Realism, Progress and the Historical Turn". Foundations of Science, 22 (1), $201-214$.

VAN FRAASSEN, B. (1980): The Scientific Image. Oxford: Oxford University Press.

VAN FRAASSEN, B. (2017): "Misdirection and Misconception in the Scientific Realism Debates". In: Agazzi, E. (ed.): Varieties of Scientific Realism: Objectivity and Truth in Science. Basil: Springer International Publishing, $95-108$.

WORRALL, J. (2011): “Miracles and Structural Realism”. In: Landry, E. - Rickless, D. (eds.): Structural Realism: Structure, Object, and Causality. Dordrecht: Springer Netherlands.

WRAY, K. B. (2013): "Success and Truth in the Realism/Anti-Realism Debate". Synthese, 190 (9), $1719-1729$.

Seungbae Park

Division of General Studies

Ulsan National Institute of Science and Technology

Ulju-gun, Ulsan 44919

The Republic of Korea

e-mail: nature@unist.ac.kr 